Table 1. Effect in FVC, DLCO, dyspnea (mMRC) and HRCT pulmonary scan after abatacept.

\begin{tabular}{|c|c|c|c|c|c|c|c|c|c|c|c|}
\hline & $\begin{array}{c}\mathrm{ABA}_{\text {MONO }} \\
\mathrm{N}=111\end{array}$ & & $\begin{array}{c}\mathrm{ABA}_{\mathrm{MTX}} \\
\mathrm{N}=46\end{array}$ & & $\begin{array}{c}\text { ABA }_{\text {NON-MTX }} \\
\quad \mathrm{N}=106\end{array}$ & & & $\begin{array}{l}\text { ABA }_{\text {MTX }} \text { vs } \\
\text { ABA }_{\text {MONO }}\end{array}$ & & $\begin{array}{c}\text { ABA }_{\text {NON-MTX }} \text { vs } \\
\text { ABA }_{\text {MONO }}\end{array}$ & \\
\hline & & $\mathrm{p}$ & & $\mathrm{p}$ & & $\mathrm{p}$ & $p^{*}$ & Unadjusted & Adjusted ${ }^{\star \star}$ & Unadjusted & Adjusted ${ }^{\star \star}$ \\
\hline $\begin{array}{l}\text { Follow-up, median [IQR] months } \\
\text { Differences between basal and }\end{array}$ & $\begin{array}{l}12[6-36] \\
\text { al follow-up }\end{array}$ & & $12[6-36]$ & & $18[12-36]$ & & 0.40 & & 0.67 & & 0.17 \\
\hline FVC, \% & $-0.5(-2.5,1.5)$ & 0.64 & $1.2(-0.6,3.1)$ & 0.17 & $-1.2(-2.9,0.5)$ & 0.17 & 0.33 & 0.30 & 0.39 & 0.59 & 0.90 \\
\hline $\begin{array}{l}\text { DLCO, \% } \\
\text { mMRC, } \mathrm{n}(\%)\end{array}$ & $1.8(-0.7,4.34)$ & 0.16 & $0.5(-3.8,4.8)$ & 0.82 & $-1.5(-4.1,1.1)$ & 0.26 & 0.20 & 0.58 & 0.80 & 0.07 & 0.32 \\
\hline $\begin{array}{l}\text { Worsening } \\
\text { Stable or improving } \\
\text { HRCT pulmonary scan, n (\%) }\end{array}$ & $\begin{array}{c}5(5) \\
93(95)\end{array}$ & & $\begin{array}{c}3(8) \\
36(92)\end{array}$ & & $\begin{array}{c}5(5) \\
87(95)\end{array}$ & & 0.83 & & 0.47 & & 0.99 \\
\hline $\begin{array}{l}\text { Worsening } \\
\text { Stable or improving }\end{array}$ & $\begin{array}{l}13(28) \\
34(72)\end{array}$ & & $\begin{array}{c}2(11) \\
19(89)\end{array}$ & & $\begin{array}{l}15(25) \\
44(75)\end{array}$ & & 0.24 & & 0.10 & & 0.78 \\
\hline $\begin{array}{l}\text { DAS28-ESR } \\
\text { Prednisone, mg/day }\end{array}$ & $\begin{array}{l}-1.5(-1.9,-1.0) \\
-3.8(-8.3,0.8)\end{array}$ & $\begin{array}{c}0.000 \\
0.10\end{array}$ & $\begin{array}{l}-1.2(-1.8,-0.6) \\
-2.7(-4.6,-0.8)\end{array}$ & $\begin{array}{l}0.000 \\
0.006\end{array}$ & $\begin{array}{l}-1.5(-1.8,-1.2) \\
-4.8(-6.3,-3.4)\end{array}$ & $\begin{array}{l}0.000 \\
0.000\end{array}$ & $\begin{array}{l}0.74 \\
0.69\end{array}$ & $\begin{array}{l}0.58 \\
0.67\end{array}$ & & $\begin{array}{l}0.92 \\
0.65\end{array}$ & \\
\hline
\end{tabular}

\section{POS0514 IMPORTANCE OF BODY MASS MEASUREMENT AND THE GRIP STRENGTH TEST TO PREDICT FALLS IN PATIENTS WITH RHEUMATOID ARTHRITIS}

M. Tada ${ }^{1}$, Y. Yamada ${ }^{2}$, K. Mandai ${ }^{3}$, N. Hidaka'. ' Osaka City General Hospital, Orthopaedic Surgery, Osaka, Japan; ${ }^{2}$ Osaka City University Medical School, Orthopaedic Surgery, Osaka, Japan; ${ }^{3}$ Osaka Saiseikai Nakatsu Hospital, Orthopaedic Surgery, Osaka, Japan

Background: We previously reported that the prevalence of sarcopenia was $28 \%$ in patients with rheumatoid arthritis (RA) in a cohort study ${ }^{1}$. RA patients have a high risk of falls and fractures ${ }^{2}$. However, the predictors of falls and fractures in RA patients are not known.

Objectives: Whether evaluation of muscle mass and function at baseline could predict falls and fractures during four-year follow-up was investigated.

Methods: The four-year follow-up data from a prospective, observational study (CHIKARA study: Correlation researcH of sarcopenla, sKeletal muscle and disease Activity in Rheumatoid Arthritis) were used. Muscle mass was measured by a body impedance analyzer, and leg muscle mass was calculated. The leg muscle score (max: 100, min: 0) reflected the ratio of leg muscle mass to overall weight. Grip strength as an indicator of muscle function was evaluated using a digital, hand-held, isokinetic dynamometer. The correlations between muscle mass or function and falls or fractures were analyzed by survival rates and Cox hazard ratios. Leg muscle mass and grip strength were investigated by receiver operating characteristic (ROC) curve analysis for correlations with falls or fractures.

Results: A total of 100 RA patients (female: $78 \%$, mean age: 66.1 years) were enrolled; 35 patients had falls, and 19 patients had fractures during the four-year follow-up. The leg muscle score, grip strength, age, and fractures at baseline were significantly correlated with falls. The cut-off values of the leg muscle score and grip strength were calculated to be 84.5 points (sensitivity: 0.79 , specificity: 0.43 ) and $15.9 \mathrm{~kg}$ (sensitivity: 0.56 , specificity: 0.70 ), respectively, by ROC curve analysis. The patients were divided into four groups by their leg muscle scores and grip strength; the numbers of falls and fractures are shown in Table 1 for each group. The fall-free survival rate was significantly lower in the group with low leg muscle score and low grip strength (35.3\%) than in the other groups ( $P=0.002)$ (Figure 1). The hazard ratio for the both low group was significantly increased, 3.6 -fold $(95 \% \mathrm{Cl}: 1.1-11.5)$, compared to that in the both high group.

Table 1. Numbers of falls and fractures by category of leg muscle score and grip strength

$L G+G S+(n=34) L G-G S+(n=12) L G+G S-(n=37) L G-G S-(n=17) P$ value $^{*}$

\begin{tabular}{llllll} 
Falls, N & 6 & 5 & 15 & 11 & 0.010 \\
Fractures, N & 3 & 4 & 6 & 6 & 0.072 \\
\hline
\end{tabular}

LG+: leg muscle score $>84.5$ points, GS+: grip strength $>15.9 \mathrm{~kg}$, LG-: leg muscle score $\leq 84.5$ points, GS+: grip strength $\leq 15.9 \mathrm{~kg}{ }^{*}$ : compared in four groups by Kruskal-Walls test.

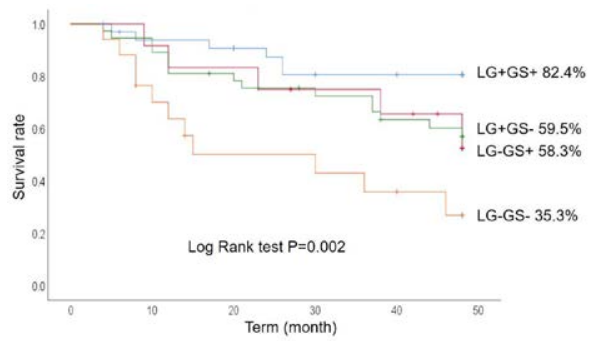

Figure 1. Fall-free survival rate in the four groups
Conclusion: RA patients with both low leg muscle score and low grip strength at baseline were at high risk for falls during the four-year follow-up period. Evaluation of muscle mass and function can predict falls in RA patients.

REFERENCES:

[1] Tada, M., Yamada, Y., Mandai, K. \& Hidaka, N. Matrix metalloprotease 3 is associated with sarcopenia in rheumatoid arthritis - results from the $\mathrm{CHI}$ KARA study. Int J Rheum Dis 21, 1962-1969, doi:10.1111/1756-185X.13335 (2018).

[2] van Staa, T. P., Geusens, P., Bijlsma, J. W., Leufkens, H. G. \& Cooper, C. Clinical assessment of the long-term risk of fracture in patients with rheumatoid arthritis. Arthritis Rheum 54, 3104-3112, doi:10.1002/art.22117 (2006).

Disclosure of Interests: None declared

DOI: 10.1136/annrheumdis-2021-eular.940

\section{POS0515 FIBROMYALGIA IN MEXICAN PATIENTS WITH RHEUMATOID ARTHRITIS}

L. D. Fajardo Hermosillo ${ }^{1} .{ }^{1}$ Instituto Mexicano del Seguro Social, Centro Médico Nacional de Occidente, Rheumatology, Guadalajara, Mexico

Background: Rheumatoid Arthritis (RA) is a disabling chronic inflammatory disease that shows an unpredictable and severe clinical course [1]. Global assessment, functional status and disease activity of patients with RA can be influenced also by non-inflammatory factors as concomitant presence of fibromyalgia (FM) $[1,2]$. FM occur up to $20 \%$ in RA patients, who present chronic widespread pain, fatigue and cognitive symptoms that impacts achieving a complete disease remission, having more comorbidities, bearing a higher medical cost and finally exhibiting a worse quality of life $[1,3,4]$. Range of manifestations of FM varies according ethnical and cultural differences between patients [1]. Here is presented the impact of fibromyalgia in Mexican patients with RA.

Objectives: To determinate the frequency and factors associated to fibromyalgia in Mexican RA patients.

Methods: 624 patients with RA that fulfilled ACR/EULAR 2010 criteria $(\geq 18$ years) from a Mexican population recruited from 2012 to 2020 were examined. Patients with or without presence of FM diagnosed by ACR 2010/2011 criteria were included. Demographic factors, clinical features, disease activity measured using DAS28 (Disease Activity Score 28-joint counts), functional status evaluated by $\mathrm{HAQ}$ (Health Assessment Questionnaire), comorbidities and pharmacologic treatments were explored for RA patients with and without FM. Charlson's comorbidity index $(\mathrm{CCl})$ was used to analyze comorbidities. Chi-square, Student's-t, U Mann-Whitney tests were performed by univariate analysis and logistic regression was executed by multivariate analysis adjusted for age and gender. Statistical tests were conducted at $5 \%$ level of significance. Results: Of 624 patients with RA $88.8 \%$ were women. The mean age [standard deviation (SD)] was 55.0 (12.3) years. The mean of time at onset of RA (SD) was 11.2 (9.1) years. A total of $311(49.8 \%)$ patients had FM; of them $91.6 \%$ were women and the mean age (SD) was 54.5 (12.2) years. In the univariate analysis RA patients with FM were more likely to be older and smokers, have seropositive RA, higher body mass index and longer time at onset of RA, show worse functional status by $\mathrm{HAQ}$ and more radiographic progression, present more extra-articular and Sicca manifestations, exhibit increased demand of hip and knee arthroplasty, also reveal a higher frequency of comorbidities including depression, osteoporosis and type 2 diabetes mellitus, besides to use a greater number of disease-modifying anti-rheumatic drugs (DMARDs), more biologic agents and higher doses of corticosteroids. Also, $\mathrm{CCl}$ was higher in RA patients with FM. Nevertheless, no differences were found for RA disease activity in both groups. In multivariate analysis, higher score of $\mathrm{CCl}$ (OR 1.21, 95\% Cl 1.01-1.44, $\mathrm{p}=0.037$ ) remained significant in RA patients with $\mathrm{FM}$. 
Conclusion: This study suggests that RA patients from Mexico have high prevalence of the FM. Those with FM have a worse functional status, a higher frequency and score of comorbidities that impact in a reduction of their quality of life. On the other hand, no differences were found for RA disease activity in both groups. However, these observations must be confirmed in larger and prospective studies. REFERENCES:

[1] Zhao SS et al. Best Pract Res Clin Rheumatol. 2019;33(3):101423;

[2] Duffield SJ et al. Rheumatology (Oxford). 2018;57(8):1453;

[3] Kim H et al. Arthritis Care Res (Hoboken) 2017;69(12):1871;

[4] Salaffi Fet al. Rheumatol Int. 2017;37(12):2035.

Disclosure of Interests: None declared

DOI: 10.1136/annrheumdis-2021-eular.1013

\section{POS0516 REDEFINING THE CLINICAL AND LABORATORY FEATURES OF RHEUMATIC PLEURAL EFFUSION: A 30-CASE SERIES}

S. Minoda ${ }^{1}$, R. Sada ${ }^{2}$, S. Matsushita ${ }^{2}$, Y. Nakayama ${ }^{3}$, H. Akebo ${ }^{2}$, Y. Tsugihashi ${ }^{4}$, H. Ishimaru ${ }^{2}, \mathrm{~K}$. Hatta ${ }^{2} .{ }^{1}$ Osaka University Graduate School of Medicine, Department of Respiratory Medicine and Clinical Immunology, Osaka, Japan; ${ }^{2}$ Tenri Hospital, Department of General Internal Medicine, Nara, Japan; ${ }^{3}$ Graduate School of Medicine, Kyoto University, Department of Rheumatology and Clinical Immunology, Kyoto, Japan; ${ }^{4}$ Tenri Health Care University, Department of Health Care, Nara, Japan

Background: Rheumatoid pleural effusion (RPE) is a common extra-articular complication in patients with rheumatoid arthritis (RA). Previous studies have shown that RPE usually occurs in middle-aged men with rheumatoid factor (RF)-positive RA. RPE usually has features of pleural fluid acidosis, high lactate dehydrogenase (LDH) levels, and very low glucose levels ${ }^{(1)}$. However, to the best of our knowledge, these findings were based on very few case series and reports, and most of these reports were published by the early $2000 \mathrm{~s}^{(1,2)}$.

Objectives: To investigate the clinical and laboratory characteristics and typical clinical courses of patients with RPE in a single centre of Japan since the beginning of the 21st century.

Methods: Medical records of RPE patients were retrospectively reviewed between May 2006 and September 2020. RPE was identified by fulfilling these five conditions: (1) confirmation of the RA diagnosis; (2) having an exudative pleural effusion according to Light's criteria; (3) negative results of pleural fluid culture; (4) negative results of pleural fluid cytology; and (5) exclusion of a parapneumonic effusion or empyema defined as no antibiotic use or ineffectiveness of antibiotics during the clinical course. Patients were divided into two groups according to their age at diagnosis: $<60$ years (Group A) and $\geq 60$ years (Group B). Results: A total of 30 cases of RPE were included in the study. The median age was 71 years (interquartile range [IQR], 66-78 years). Of these patients, $16(53 \%)$ were women. The median disease duration of RA was 98 months (IQR, 8-162 months). The two groups comprised six patients aged $<60$ years old and 24 patients $\geq 60$ years. The median age was 54 years (IQR, 49-56 years) in Group A and 74 years (IQR, 69-78 years) in Group B. The median disease duration of RA was longer in Group B than that in Group A (132 vs. 3 months, $p=0.008$ ). Compared with Group A, Group B had fewer patients with fever ( $14 \%$ vs. $83 \%, p=0.003)$, and had lower serum C-reactive protein levels (3.3 vs. $11.1 \mathrm{mg} / \mathrm{dL}, \mathrm{p}=0.03$ ). Moreover, Group B was more likely to show mild inflammatory pleural fluids with higher $\mathrm{pH}(7.5$ vs. $7.2, \mathrm{p}=0.005)$ and lower $\mathrm{LDH}$ levels (155 vs. $1810 \mathrm{IU} / \mathrm{L}, \mathrm{p}=0.046)$. Corticosteroids were started or increased in five (83\%) and nine $(38 \%)$ patients, and biologic disease-modifying anti-rheumatic drugs were started in one (17\%) and two (8\%) patients in groups A and B, respectively. One patient (16\%) died within 5-years in Group A, and seven patients (29\%) died in Group B. Conclusion: In contrast to previous studies, RPE was seen in older patients as well as middle-aged adults, and the pleural fluid analysis in older patients with RPE showed milder inflammation than the middle-aged patients.

Table 1. Comparison of clinical and laboratory findings between Group A and Group B.

\begin{tabular}{|c|c|c|c|}
\hline & Group A $(n=6)$ & Group B $(n=24)$ & $\begin{array}{c}P \\
\text { value }\end{array}$ \\
\hline$\overline{\text { Age (years) }}$ & 54 [49-56] & 74 [69-78] & \\
\hline Female & $2(n=6,33.3)$ & $14(n=24,58.3)$ & 0.38 \\
\hline Disease duration of RA (months) & $3[1-9]$ & $132[44-199]$ & 0.008 \\
\hline Fever $\geq 37.0^{\circ} \mathrm{C}$ & $5(n=6,83.3)$ & $3(n=22,13.6)$ & 0.003 \\
\hline $\begin{array}{l}\text { Serum } \\
\text { CRP (mg/dL) }\end{array}$ & $11.1[5.6-1.4]$ & $3.3[0.9-10.5]$ & 0.03 \\
\hline $\mathrm{RF}(\mathrm{IU} / \mathrm{mL})$ & $100[19-816]$ & $63[23-193]$ & 0.95 \\
\hline $\begin{array}{l}\text { Anti-CCP ab positive } \\
\text { Pleural fluid analysis }\end{array}$ & $5(n=6,83.3)$ & $12(n=15,80)$ & 1.00 \\
\hline $\mathrm{pH}$ & $7.2[7.2-7.2]$ & $7.5[7.4-7.5]$ & 0.005 \\
\hline $\mathrm{LDH}(\mathrm{IU} / \mathrm{L})$ & $1810[594-2932]$ & $155[123-346]$ & 0.046 \\
\hline $\mathrm{Glu}(\mathrm{mg} / \mathrm{dL})$ & $59[10-123]$ & $105[91-122]$ & 0.42 \\
\hline$T p(g / d L)$ & $5.1[4.9-5.6]$ & $4.6[3.6-5.2]$ & 0.21 \\
\hline Number of cells $(/ \mu \mathrm{L})$ & $5235[3353-9300]$ & $3300[1490-5008]$ & 0.27 \\
\hline Glu/serum Glu & $0.41[0.09-0.99]$ & $1.05[0.85-1.15]$ & 0.71 \\
\hline Started or increased CS & $5(n=6,83.3)$ & $9(n=24,37.5)$ & 0.18 \\
\hline Started bDMARDs & $1(n=6,16.6)$ & $2(n=24,8.3)$ & 0.50 \\
\hline Died within 5 years & $1(n=6,16.6)$ & $7(n=24,29.1)$ & 1.00 \\
\hline
\end{tabular}

Data are median [interquartile range], or number (total number, percent).Abbreviations: RA, rheumatoid arthritis; CRP, C-reactive protein; RF, rheumatoid factor; Anti-CCP ab, anti-cyclic citrullinated peptide antibodies; LDH, lactate dehydrogenase; Glu, glucose; Tp, total protein; $\mathrm{CS}$, corticosteroid; bDMARDs, biologic disease-modifying anti-rheumatic drugs
REFERENCES:

[1] Balbir-Gurman A, et al. Semin Arthritis Rheum. 2006 Jun; 35(6): 368-78. Figure. Comparison of pleural fluid lactate dehydrogenase (LDH) and $\mathrm{pH}$ between Group A and Group B.
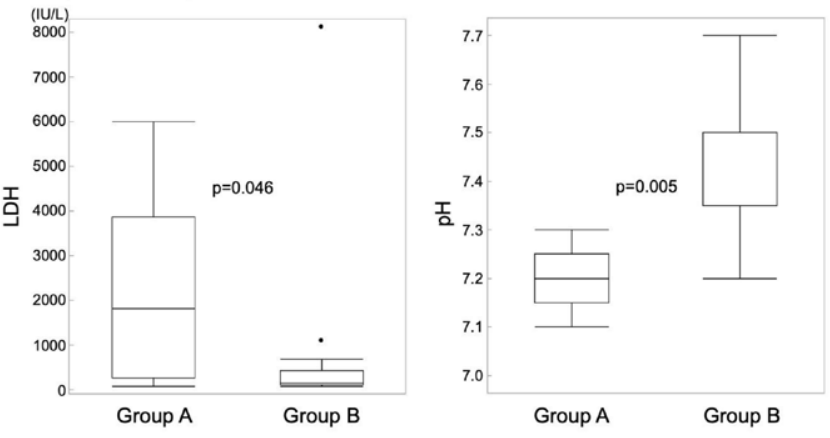

Disclosure of Interests: None declared DOI: 10.1136/annrheumdis-2021-eular.1197

\section{\begin{tabular}{|l|l}
\hline POS0517 & A LONGITUDINAL STUDY OF SARCOPENIA,
\end{tabular} LOCOMOTIVE SYNDROME, AND FRAILTY IN PATIENTS WITH RHEUMATOID ARTHRITIS: FROM THE CHIKARA STUDY}

K. Mandai ${ }^{1}$, M. Tada ${ }^{2}$, Y. Yamada ${ }^{3}$, T. Koike ${ }^{4,5}$, T. Okano $^{3}$, N. Hidaka ${ }^{2}$,

H. Nakamura ${ }^{3}$. ${ }^{1}$ Osaka Saiseikai Nakatsu Hospital, Department of Orthopedic Surgery, Osaka, Japan; ${ }^{2}$ Osaka City General Hospital, Department of Orthopedic Surgery, Osaka, Japan; ${ }^{3}$ Osaka City University Graduate School of Medicine, Department of Orthopedic Surgery, Osaka, Japan; ${ }^{4}$ Osaka City University Graduate School of Medicine, Center for Senile Degenerative Disorders (CSDD), Osaka, Japan; ${ }^{5}$ Search Institute for Bone and Arthritis Disease (SINBAD), Department of Orthopedic Surgery, Shirahama, Japan

Background: Rheumatoid arthritis (RA) patients have a high frequency of sarcopenia and they commonly have reduced physical function. We previously reported that the prevalence of sarcopenia was $28 \%$, that of frailty was $18.9 \%$, and that of pre-frailty was $38.9 \%$ in RA patients ${ }^{1,2}$, and $13.2 \%$ of RA patients developed sarcopenia within a year ${ }^{3}$. Objectives: To investigate the risk factors for new onset of sarcopenia, locomotive syndrome, and frailty in patients with RA and the course of each disease. Methods: Two-year follow-up data from the rural group of the prospective, observational CHIKARA study were used. Sarcopenia was diagnosed using the criteria of the Asian Working Group for Sarcopenia 2014, locomotive syndrome was diagnosed using locomotive 5 , and frailty was diagnosed using the basic checklist. New onset of the disease over the 2-year follow-up period was studied, excluding cases that had the disease at baseline. Improvement was defined as cases with disease at baseline that no longer met the diagnostic criteria after 2 years. Differences in the characteristics of each disease were tested using the Chi-squared test and the paired $t$-test. Results: The 81 patients with RA ( $82.7 \%$ female) had mean age $66.9 \pm 11.5$ years, mean DAS28-ESR $2.9 \pm 1.2$, methotrexate use in $81.5 \%$ (with a dose of $9.9 \pm 2.7 \mathrm{mg}$ / week), and glucocorticoid (GC) use in $22.2 \%$ (with a dose of $3.1 \pm 1.7 \mathrm{mg} /$ week). The baseline prevalence was $44.4 \%$ for sarcopenia, $35.8 \%$ for locomotive syndrome, and $25.9 \%$ for frailty, and the new onset rate was $4.4 \%$ for sarcopenia, $15.4 \%$ for locomotive syndrome, and $13.3 \%$ for frailty. Of the patients with each disease at baseline, $36.1 \%$ had sarcopenia, $20.7 \%$ had locomotive syndrome, and $33.3 \%$ had frailty, and of those with each disease at 2 years, $36.1 \%$ had sarcopenia, $20.7 \%$ had locomotive syndrome, and $33.3 \%$ had frailty. The new onset sarcopenia and locomotive syndrome groups had significantly higher rates of GC use $(p=0.036$, $\mathrm{p}=0.007$, paired $t$-test) and significantly higher doses $(\mathrm{p}=0.01, \mathrm{p}=0.001$, paired $t$-test $)$ than the groups without new onset sarcopenia and locomotive syndrome. High baseline disease activity was an independent predictor of new onset of locomotive syndrome on multivariate logistic regression analysis ( $O R=3.21, p=0.015)$.

Conclusion: The new onset rates at 2 years were $4.4 \%$ for sarcopenia, $15.4 \%$ for locomotive syndrome, and $13.3 \%$ for frailty. In the new onset sarcopenia and locomotive syndrome groups, both GC use and dosage were significantly higher. REFERENCES:

[1] Tada $M$, et al. Matrix metalloprotease 3 is associated with sarcopenia in rheumatoid arthritis - results from the CHIKARA study. Int $\mathrm{J}$ Rheum Dis. 2018 Nov;21(11):1962-1969.

[2] Tada $M$, et al. Correlation between frailty and disease activity in patients with rheumatoid arthritis: Data from the CHIKARA study. Geriatr Gerontol Int. 2019 Dec;19(12):1220-1225.

[3] Yamada Y, et al. Glucocorticoid use is an independent risk factor for developing sarcopenia in patients with rheumatoid arthritis: from the CHIKARA study. Clin Rheumatol. 2020 Jun;39(6):1757-1764.

Disclosure of Interests: None declared

DOI: 10.1136/annrheumdis-2021-eular.1245 